\title{
Características edafoclimáticas e informações socioeconômicas no diagnóstico de agroecossistemas da região de São Carlos, $\mathrm{SP}^{(1)}$
}

\author{
Luís Fernando Guedes Pinto(2) e Silvio Crestana(3)
}

Resumo - O planejamento regional de agroecossistemas é um componente fundamental para a sustentabilidade da atividade agrícola, devendo considerar a realidade biofísica e socioeconômica. A agropecuária cumpre importante papel na região de São Carlos, SP, porém esta localiza-se em grande parte numa área de preservação ambiental. Este trabalho visou delimitar a Zona Agroecológica dessa região e diagnosticar seus agroecossistemas por meio de informações edafoclimáticas e socioeconômicas. A delimitação foi baseada no clima, geomorfologia e divisão administrativa. Da área delimitada estudou-se o clima, pedologia, uso da terra, estrutura fundiária e o manejo dos agroecossistemas. A Zona delimitada ocupa 286.824,08 ha, e é composta pelos municípios de Analândia, Itirapina, Santa Maria da Serra, São Carlos, São Pedro e Torrinha. Há potencial para a atividade agrícola, ocorrendo principalmente solos arenosos e de baixa fertilidade. Pastagens e cana-de-açúcar são os usos predominantes; a distribuição da posse da terra é desigual, e existe risco de degradação ambiental, pois não se empregam práticas compatíveis com as características naturais. Recomenda-se o uso de práticas que maximizem a conservação do solo, sua correção, e o aproveitamento de seus nutrientes, assim como o cultivo de espécies adaptadas a solos arenosos, que sejam pouco exigentes em fertilidade e resistentes a estresse hídrico.

Termos para indexação: ecossistema, sistema de produção, planejamento, zonas agroclimáticas.

\section{Soil and climate characteristics and socio-economic data in the diagnostic of agroecosystems of São Carlos region, SP, Brazil}

\begin{abstract}
Abstratct - Regional planning of agroecosystems is a key component in the sustainability of agriculture and it should consider the biophysical and socio-economic reality. Agriculture plays an important role in the region of São Carlos, SP, Brazil, but it is located in an area of environmental conservation. This work aimed to delimit the Agroecological Zone of this region and to diagnose agroecosystems through soil, climate and socio-economic data. The delimitation was based on climate, geomorphology and administrative division of the counties. The soils, land use, distribution of land ownership and the management were studied. The Zone delimited occupies $286,824.08 \mathrm{ha}$, and is composed by the Analândia, Itirapina, Santa Maria da Serra, São Carlos, São Pedro and Torrinha counties. There is potential for agriculture, existing mainly sandy and low fertility soils. Pastures and sugar cane are the main land use, the distribution of the ownership is unequal and there is risk of environmental degradation because the farmers do not use practices compatible with the natural features. It is recommended to adopt practices that emphasize soil conservation and correction and nutrient uptake. Species adapted to sandy soils with low demand for nutrients and resistant to water stress should be cultivated.
\end{abstract}

Index terms: ecosystems, farming systems, planning, agroclimatic zones.

(1) Aceito para publicação em 5 de dezembro de 2000. Extraído da Dissertação de Mestrado apresentada pelo primeiro autor à Universidade de São Paulo (USP), Escola de Engenharia de São Carlos, Centro de Recursos Hídricos e Ecologia Aplicada, São Carlos, SP.

\footnotetext{
(2) Escola Superior de Agricultura Luiz de Queiroz, Rua Alexandre Fleming, 875, CEP 13092-340 Campinas, SP. Bolsista do CNPq. E-mail: lfgpinto@carpa.ciagri.usp.br

(3) Embrapa-Centro Nacional de Pesquisa e Desenvolvimento de Instrumentação Agropecuária, Rua XV de Novembro, 1452, CEP 13560-970 São Carlos, SP. E-mail: crestana@cnpdia.embrapa.br
} 


\section{Introdução}

Na pesquisa de sistemas de produção e de técnicas que permitam a compatibilização da produção agrícola com o desenvolvimento sustentado, o diagnóstico e planejamento de agroecossistemas é um dos elementos essenciais. Garrity \& Agustin (1995) propõem que a identificação de problemas e a avaliação e pesquisa de opções de manejo em sistemas de produção envolvam a análise espacial e quantitativa do uso da terra, que permitem identificar seus potenciais e limitações. Para a FAO (1996), o Zoneamento Agroecológico define Zonas na base de combinações entre solos, relevo e demais características limitantes, priorizando parâmetros direcionados para as exigências climáticas e edáficas das culturas e nos sistemas de produção em que estão inseridas. Cada Zona tem uma combinação similar de potenciais e restrições para uso da terra e serve como referência para recomendações com o fim de incrementar o seu uso presente, aumentando sua produção ou limitando sua degradação.

A região de São Carlos localiza-se no centro do Estado de São Paulo, fazendo parte da província geomorfológica das Cuestas Basálticas e sua altitude é da ordem de 800 a 900 metros. Segundo Universidade de São Paulo (1980), o clima da região é classificado como Cwa (Köppen), isto é, subtropical mesotérmico, úmido, com chuvas de verão, e estiagem branda no inverno. A estação chuvosa vai de outubro a março e a estação seca de abril a setembro. De acordo com Verdade et al. (1974), a área se encontra na faixa de isoterma anual de 19 a $20^{\circ} \mathrm{C}$, e a isoterma do mês mais frio (julho) é entre 15 e $16^{\circ} \mathrm{C}$. A deficiência hídrica anual varia de 20 a $40 \mathrm{~mm}$, distribuindo-se em: abril-maio, 0 a $10 \mathrm{~mm}$; junho-julho, 0 a $10 \mathrm{~mm}$; agosto-setembro, 20 a $40 \mathrm{~mm}$. Há ocorrência esporádica de geadas.

A agropecuária tem importante papel na região, porém esta encontra-se numa área de grande importância ecológica, o que requer sistemas de produção e técnicas conservacionistas adequadas a sua realidade biofísica (Pinto, 1996). Quanto às características naturais (clima e solos), a região está apta para a utilização do sistema de plantio direto, porém devese pesquisar os sistemas adequados de rotação de culturas e adubos verdes (Fancelli et al., 1985).
Os trabalhos para identificação de espécies de adubos verdes com potencial para serem empregadas na região foram iniciados por Pinto \& Crestana (1998). De maneira complementar, sistemas agroflorestais têm potencial para compatibilizar altos rendimentos agropecuários com conservação do solo e biodiversidade em diferentes ambientes edafoclimáticos e realidades socioeconômicas (Sanchez, 1995).

O objetivo deste trabalho foi delimitar a Zona Agroecológica da região de São Carlos, SP, e diagnosticar seus agroecossistemas por meio de características edafoclimáticas e informações socioeconômicas.

\section{Material e Métodos}

A delimitação da Zona Agroecológica foi feita com base em informações de características naturais (clima e geomorfologia) e administrativas. Utilizaram-se os seguintes mapas: A) Isotermas anuais do Estado de São Paulo, Instituto Agronômico (IAC), escala 1:2.000.000; B) Deficiência hídrica anual do Estado de São Paulo, IAC, 1:2.000.000; C) Mapa das Divisões Geomorfológicas do Estado de São Paulo, IPT, 1:500.000; D) Mapa da Divisão Municipal e Distrital do Estado de São Paulo, Instituto Geográfico e Cartográfico de São Paulo, 1:2.000.000.

Digitalizou-se a porção dos mapas A, B, C e D, referente à característica mais limitante ou exclusiva da região de São Carlos; do mapa $\mathrm{A}$, digitalizou-se a região da isoterma anual de valor 20 a $21^{\circ} \mathrm{C}$; do mapa $\mathrm{B}$, a região do mapa de isolinhas de valor 20 a $40 \mathrm{~mm}$, e do mapa C, a região das Cuestas Basálticas

A Zona Climática comum onde está inserida a região de São Carlos foi obtida através da intersecção entre as imagens de isoterma anual, e de deficiência hídrica anual. Em seguida, esta zona climática foi sobreposta à região geomorfológica local. A interseção de ambas foi chamada de Zona Agroecológica e admitida como uma área homogênea para o planejamento da atividade agrícola em âmbito regional. Contudo, os dados a serem levantados sobre os sistemas de produção e agroecossistemas desta região encontravam-se sobre a delimitação administrativa dos municípios. Assim, foi feita nova interseção, da Zona Agroecológica da região de São Carlos com a Região Administrativa dos municípios da região de São Carlos. Foram selecionados os municípios que tivessem pelo menos $20 \%$ de sua área coincidentes com a Zona Agroecológica. A região resultante foi a área de estudo deste trabalho, a qual denominou-se de Zona Agroecoadministrativa de São Carlos 
Para o estudo dos solos existentes na região, selecionaram-se as Cartas de Solo do Estado de São Paulo (levantadas pela seção de Pedologia do IAC), na escala 1:100.000. Utilizaram-se as quadrículas Descalvado, São Carlos, Piracicaba e Brotas. Com base nestas Cartas, foram identificadas as principais associações de solos ocorrentes na área de estudo, e descritas a textura e fertilidade (ambos do horizonte superficial). Cada associação foi representada pelo nome do solo predominante, isto é, o primeiro da associação apresentada na carta do IAC, o que foi obtido digitalizando-se as quadrículas pedológicas do IAC, na área coincidente com a Zona Agroecoadministrativa de São Carlos. Após a digitalização das quadrículas pedológicas, os solos foram reclassificados em duas imagens distintas, de acordo com a textura e a fertilidade. Quanto à fertilidade, os solos foram classificados em álicos, distróficos ou eutróficos, e quanto à textura, em arenosos ou argilosos. Os solos de textura média foram classificados como arenosos. Tal simplificação do método justifica a presença de Latossolos Arenosos, que não ocorrem na natureza. Em seguida, foi feita uma nova intersecção entre as imagens de textura e fertilidade, obtendo-se as Zonas Edáficas dos solos da região.

Para melhor compreensão da realidade dos agroecossistemas da região, coletaram-se as seguintes informações socioeconômicas: 1) Uso da terra da região em 1994, isto é, quais culturas foram produzidas na região e que área ocupavam; estas informações foram coletadas diretamente no Instituto de Economia Agrícola (IEA), da Secretaria da Agricultura do Estado de São Paulo; as áreas das culturas exploradas e os rendimentos obtidos por elas foram obtidos pelo Levantamento Subjetivo no municí- pio, realizado pelas Casas de Agricultura locais; 2) Estrutura fundiária da região, para verificar quais os tipos de propriedade e agricultor existem, e se há dominância de algum padrão; os dados foram levantados no Censo agropecuário do IBGE de 1985 (IBGE, 1991); 3) Dados adicionais sobre os estabelecimentos rurais que compõem os sistemas de produção da região, existentes no Censo do IBGE de 1985; foram levantadas informações sobre utilização de assistência técnica, uso e procedência de energia utilizada nos trabalhos, uso de defensivos e fertilizantes, e uso de práticas conservacionistas pelos estabelecimentos

\section{Resultados e Discussão}

A Zona Agroecoadministrativa delimitada para a região de São Carlos localiza-se entre as latitudes $21^{\circ} 32^{\prime} \mathrm{S}$ e $22^{\circ} 36^{\prime} \mathrm{S}$ e as longitudes $47^{\circ} 33^{\prime} \mathrm{W}$ e $48^{\circ} 18^{\prime} \mathrm{W}$, ocupando uma área total de $286.824,08$ ha. É composta pelos municípios de Analândia, Itirapina, Santa Maria da Serra, São Carlos, São Pedro e Torrinha. Todos os municípios da Zona Agroecoadministrativa possuem uma grande parte de sua área dentro da delimitação da APA (Área de Preservação Ambiental) Corumbataí - Perímetro Corumbataí: Analândia, 80,93\%; Itirapina, 100\%; Santa Maria da Serra, $100 \%$; São Carlos, $13 \%$; São Pedro, 84,71\%, e Torrinha, 78,43\%.

A Tabela 1 apresenta os principais solos das associações ocorrentes na Zona Agroecoadministrativa,

Tabela 1. Solos da Zona Agroecoadministrativa de São Carlos, em áreas de ocorrência absoluta e relativa(1).

\begin{tabular}{lcc}
\hline Solo & Área absoluta (ha) & Área relativa (\%) \\
\hline Podzólico Vermelho-Amarelo álico, arenoso & 16.192 & 5,84 \\
Podzólico Vermelho-Amarelo distrófico, arenoso & 20.493 & 7,39 \\
Podzólico Vermelho-Escuro eutrófico, argiloso & 112 & 0,04 \\
Terra Roxa Estruturada eutrófica, argilosa & 2.132 & 0,77 \\
Terra Roxa Estruturada distrófica, argilosa & 1.205 & 0,43 \\
Latossolo Vermelho-Amarelo álico, arenoso & 82.769 & 29,84 \\
Latossolo Vermelho-Amarelo álico, argiloso & 21.396 & 7,71 \\
Latossolo Roxo eutrófico, argiloso & 4.122 & 1,49 \\
Latossolo Roxo distrófico, argiloso & 21.746 & 7,84 \\
Latossolo Vermelho-Escuro álico, argiloso & 7.700 & 2,78 \\
Latossolo Vermelho-Escuro álico, arenoso & 10.463 & 3,77 \\
Areia Quartzosa álica, arenosa & 54.464 & 19,64 \\
Litólico eutrófico, argiloso & 25.434 & 9,17 \\
Hidromórfico & 9.042 & 3,26 \\
\hline Total & 277.364 & 100,00 \\
\hline
\end{tabular}

${ }^{(1)} \mathrm{A}$ área total é inferior à da Zona Agroecoadministrativa, pois não há cartas de solo disponíveis para a Quadrícula Botucatu. 
classificados em fertilidade e textura. Há predominância de Latossolos Vermelho-Amarelo e Areias Quartzosas, ocupando 56\% da área total. Em seguida, aparecem os Podzólicos Vermelho-Amarelo, com $13 \%$, e os Litólicos ocorrendo em 9,17\% da área total. Os solos Hidromórficos ocorrem em áreas alagadas e margens de rios, e foram indicados como áreas de proteção ambiental. Verifica-se a dominância de solos de textura arenosa $(78,38 \%)$ e pequena ocorrência de solos argilosos $(21,62 \%)$. Na região, $88,15 \%$ dos solos são de baixa fertilidade, sendo $71,95 \%$ álicos e 16,2\%, distróficos. Apenas 11,86\% dos solos são eutróficos. Foram identificadas seis Zonas Edáficas e sua distribuição quantitativa e relativa pode ser verificada na Tabela 2 . Os solos arenosos e álicos ocupam $65,66 \%$ da área total estudada. Há condições favoráveis para ocorrência de nematóides, situação comum nos solos arenosos do Estado de São Paulo, e a aplicação de calcário e fósforo são as principais medidas de correção necessárias a estes.

Mais da metade da área total (53\%) está ocupada por pastagens; $19 \%$, por cana-de-açúcar; $13 \%$, por culturas perenes (citrus, café e reflorestamento), e apenas $4 \%$, por culturas anuais, restando $9 \%$ para vegetação nativa (mata, cerrado e cerradão).

A análise da estrutura fundiária revelou que 5,44\% dos grandes estabelecimentos ocupam $43,17 \%$ da área total, enquanto $28,4 \%$ dos pequenos estabelecimentos ocupam apenas $2,03 \%$. Sobre o padrão de estabelecimentos presente na área, $71,34 \%$ da área é

Tabela 2. Área absoluta e relativa das zonas edáficas da Zona Agroecoadministrativa de São $\operatorname{Carlos}^{(1)}$.

\begin{tabular}{lcc}
\hline Zona & $\begin{array}{c}\text { Área absoluta } \\
\text { (ha) }\end{array}$ & $\begin{array}{c}\text { Área relativa } \\
(\%)\end{array}$ \\
\hline Arenosa, álica & 163.888 & 65,66 \\
Arenosa, distrófica & 42.239 & 16,92 \\
Arenosa, eutrófica & 4.122 & 1,65 \\
Argilosa, álica & 29.096 & 11,65 \\
Argilosa, distrófica & 1.205 & 0,48 \\
Argilosa, eutrófica & 9.042 & 3,62 \\
\hline Total & 249.592 & 100,00 \\
\hline (1)A área total é inferior a área total dos solos, pois os solos Hidromórficos \\
não foram contabilizados.
\end{tabular}

Pesq. agropec. bras., Brasília, v. 36, n. 11, p. 1325-1329, nov. 2001 ocupada por estabelecimentos entre 100 e 2.000 ha, e que $66,2 \%$ do número total de estabelecimentos estão na faixa entre 20 e 500 ha.

Os dados adicionais coletados sobre os sistemas de produção são contrastantes. Do total de estabelecimentos rurais, $38 \%$ utilizam assistência técnica, porém somente $21,3 \%$ a utilizam para produção vegetal. Os estabelecimentos em questão são mecanizados, pois $71,5 \%$ destes utilizam força mecânica. Fertilizantes são usados por $82,4 \%$ dos estabelecimentos, sendo que $74 \%$ o utilizam na forma química. Além disso, $85 \%$ dos estabelecimentos utilizam defensivos químicos. Porém, o dado mais relevante é relativo ao uso de calcário que, como já discutido anteriormente, é o insumo mais importante para os solos da região, pois fornece maior resposta em produção, a um custo relativamente baixo. Contudo, apenas 35\% dos estabelecimentos utilizam calcário. Do total de estabelecimentos da região, 57\% utilizam técnicas de conservação de solo, e apenas 10,5\% utilizam a técnica de terraceamento, apesar de localizar-se em região com altas declividades e solos susceptíveis à erosão.

\section{Conclusões}

1. A região Agroecoadministrativa de São Carlos possui potencial edafoclimático para a atividade agrícola.

2. O uso da terra é pouco diversificado, e a distribuição da posse da terra é desigual.

3. As práticas agrícolas atuais são inadequadas para as características naturais da região, implicando um risco de degradação ambiental e baixo aproveitamento do seu potencial produtivo.

\section{Referências}

FANCELLI, A. L.; TORRADO, P. V.; MACHADO, J. Atualização em plantio direto. Campinas: Fundação Cargill, 1985. $343 \mathrm{p}$

FAO (Roma, Itália). Agroecological zoning guidelines Rome, 1996. 78 p. (Soils Bulletin, 73).

GARRITY, D. P.; AGUSTIN, P. C. Historical land use evolution in a tropical acid upland agroecosystem. 
Agriculture, Ecosystems and Environment,Amsterdam, v. 53, n. 1, p. $83-95,1995$.

IBGE (Rio de Janeiro, RJ). Censo agropecuário de 1985 São Paulo. Rio de Janeiro, 1991. v. 21

PINTO, L. F. G. Estudo prospectivo visando o planejamento do uso da adubação verde nos agroecossistemas de São Carlos, SP. São Carlos: USP, 1996. 87 p. Dissertação de Mestrado.

PINTO, L. F. G.; CRESTANA, S. Estudo prospectivo visando o planejamento do uso da adubação verde nos agroecossistemas de São Carlos. Revista Brasileira de Ciência do Solo, Campinas, v. 22, n. 2, p. 329-336, 1998

SANCHEZ, P. A. Science in agroforestry. Agroforestry Systems, Dordrecht, v. 30, n. 5-55, 1995.

VERDADE, F. da C.; DIAS, C. A.; SILVA, G. L. S. P. da; MELLO, M. D. H. de; VICTOR, M. A. de M. Zoneamento agrícola do Estado de São Paulo. São Paulo: Secretaria da Agricultura, 1974. v. 1

UNIVERSIDADE DE SÃO PAULO. Escola de Engenharia de São Carlos. Bacia experimental rio Jacaré-Guaçu, São Carlos. São Carlos, 1980. p. 24-25 